\title{
Sedimentary Record of Ancient Coastal Upwelling
}

\author{
by Jörn Thiede and Erwin Suess
}

\begin{abstract}
Coastal upwelling is a large-scale perturbalion of the surface and subsurface ocean circulation which develops along coastlines in response to specific elements of the tropospheric circulation. In this article the authors review geological aspects of coastal upwelling, including the responses of the sedimentary regime and the preservation of upwelling "signals" in the geological record.
\end{abstract}

\section{What is Coastal Upwelling?}

Along the west coasts of continents in both hemispheres there are prevailing winds that blow toward the equator as a result of quasi-stationary high pressure systems in the midoceans. These winds result in an offshore movement of water perpendicular to the wind-induced surface stress. This transport occurs in a layer several tens of meters thick and is a function of the stratification and the stress in the fluid. Because of the continuity of the system, the surface water transported away from the coast must be replaced near the coast by water from the subsurface (Sverdrup et al., 1942; Smith, in Suess and Thiede, 1983). Generally such upwelled water has significantly lower temperatures, higher salinities and much higher nutrient concentrations than the replaced surface water.

The configuration of modern oceans and climatic zonation have led to the development of four major areas of yearround coastal upwelling as part of the eastern boundary currents of the Atlantic and Pacific oceans: off northwest Africa, southwest Africa, western North America, and northwestern South America (Fig. 1). A major seasonal upwelling area also exists along the nor thwestern rim of the Indian ocean basin in response to monsoonal wind regimes there. In addition, locally persistent coastal upwelling may develop anywhere in surface waters when segments of coast-lines, or even ice margins, parallel regional surface wind regimes.

The physical and biological aspects of coastal upwelling have been examined in several multi-institutional research projects (Richards, 1981; Longhurst, 1981; Hempel, 1982). However, the geological aspects have only recently been the subject of a comprehensive review and assessment. The occasion for this was an advanced research institute held in September 1981 in Vilamoura, Portugal, the proceedings of which have now been published in two volumes (Suess and Thiede, 1983; Thiede and Suess, 1983).

Responses of the Sedimentary Regime to Coastal Upwelling It has been known for some time that the sediments under coastal upwelling regimes are different from those of the adjacent shelf and slope, in that they contain higher organic carbon concentrations, accumulations of phosphorites and significant diatomaceous components. They must therefore record some complex "signal" of upweiling oceanography (Brongersma-Sanders, 1948). However, the details have remained vague as to how these signals should be understood in terms of increased salinities, higher nutrient concentrations and bioproductivity, and lower temperatures.

From circulation modelling it is clear that coastal upwelling systems are extraordinarily responsive to local and global
Figure 1: The five major coastal upwelling regions of the world (black), sea level atmospheric pressure systems and major currents (arrows) that influence them. The dashed circles represent mean idealized positions of isobars during the season of strongest upwelling (from Hartline, 1980).

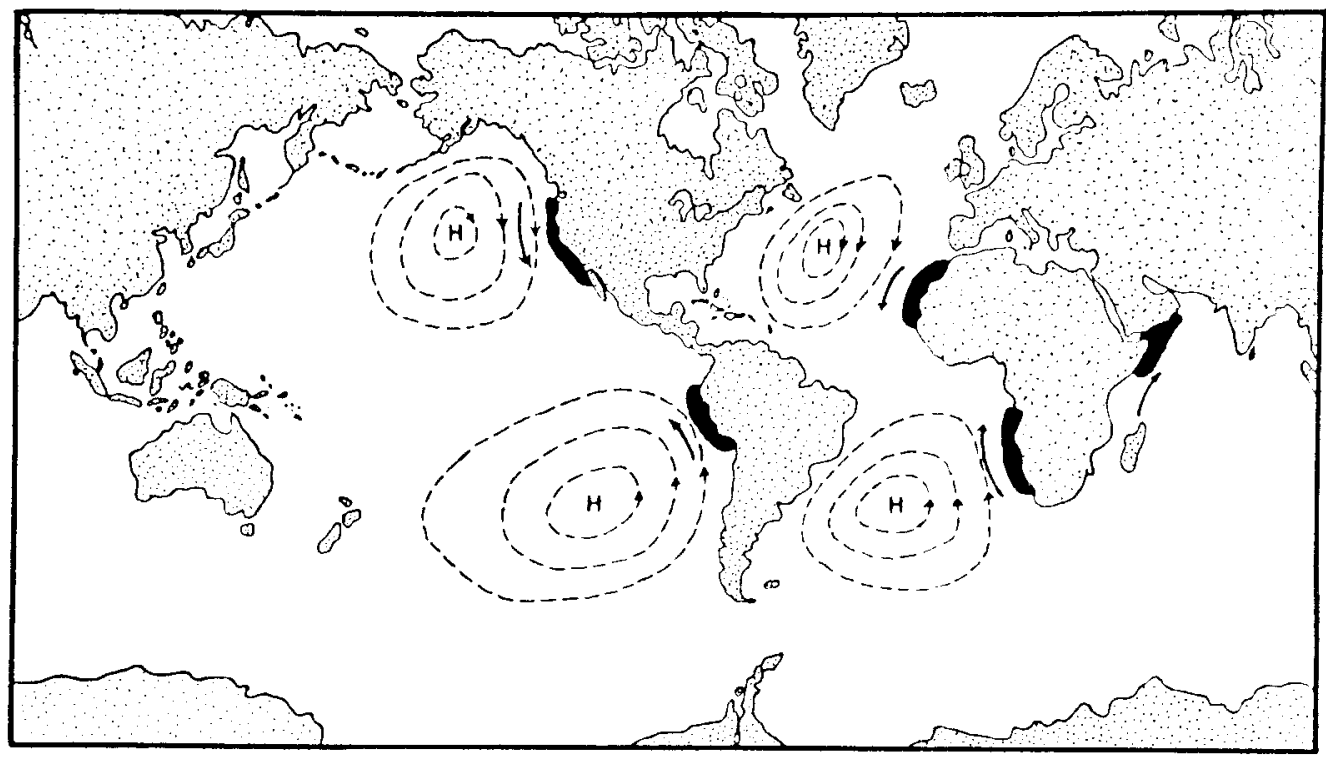


Figure 2: Schematic ilustration of $(a)$ timescales and (b) distance lingths of oceanic phenomena and of the resolvable geologic record preserved in the sediments. A typical upwelling event lasts from a few days to several weeks.
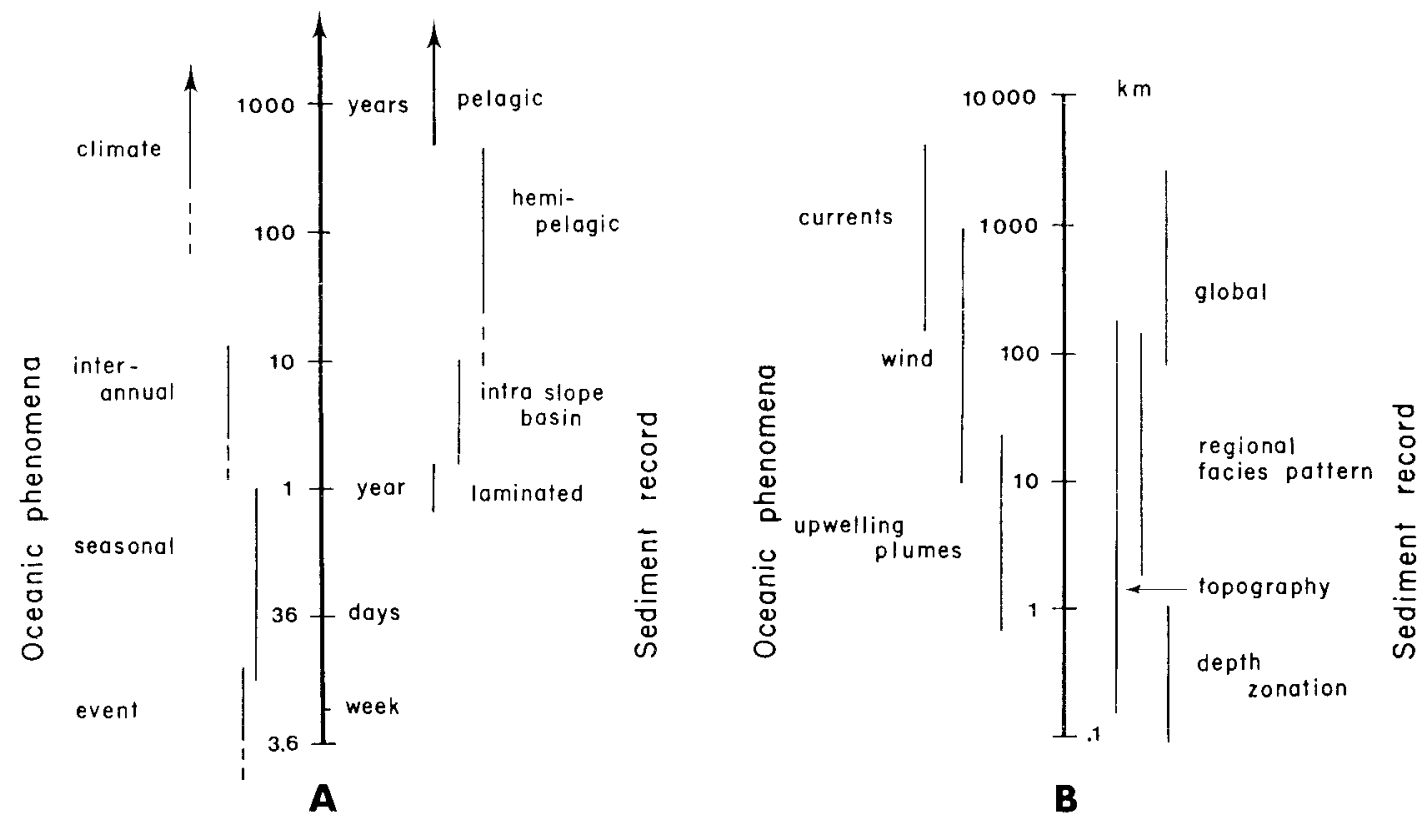

B

welling conditions. It also adversely affects time-series measurements of the "indicator parameters". The nature of geological samples in general does not allow the identification of events of less than one year in duration, unlike the laminations of sediments or growth rhythms documented from marine shell material.

Such high, resolution records are available only from very few localities, often not in an optimal geographic position for prolonged upwelling to have occurred, and they usually cover only the recent geologic past, such as the Tertiary and Quaternary. Thus, in most cases the preserved upwelling signals record oceanographic processes averaged over a much longer time than in the case of modern oceanographic observations (Fig. 2). It is not clear how this "smoothing function" changes the sediment properties; rapid changes in the hydrography of upwelling regimes might prevent the geologic record from accumulating enough detail.

An example of just such a "smoothing" problem may be the controversy over whether or not Quaternary phosphorites (Fig. 3) formed as a result of coastal upwelling in western boundary current regimes off eastern Australia or the southeastern United States (Burnett et al., and $\mathrm{O}^{\prime} \mathrm{Brien}$ and Veeh, both in Suess and Thiede, 1983). It is possible that the slowgrowing Holocene phosphorite nodules at western boundary current regimes off these regions began forming in preHolocene times when these regimes were subjected to coastal upwelling.

Geologists generally attempt to interpret geological records in terms of the dynamics of modern upwelling regimes. However, when looking back into the geologic past, we encounter situations without modern analogs, and it remains to be seen if insights into contemporary processes can adequately describe ancient oceans and their upwelling regimes. The situations for which we do not have modern counterparts may be a result of the interaction of the dynamics of the lithosphere, atmosphere, hydrosphere and biosphere. These change through time and jointly control the evolution of the depositional environments in the oceans and along continental margins. A change in one of the elements of the global palaeoenvironment will often find a response in another, but the nature of the geological record prevents us from establishing the proper causal relationships among these changes.

\section{Contrasts Between Modern and Ancient Upwelling Regimes}

We have no modern observations to guide our interpretations of the geologic past, when the physiography of the global 


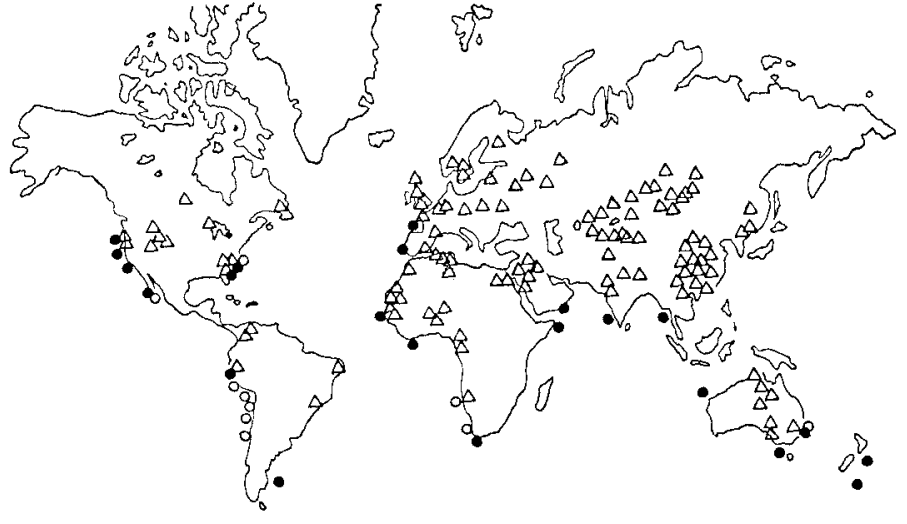

Figure 3: Global sedimentary phosphorite occurrences. Deposits shown on land $(\Delta)$ include all ages. Submarine deposits are divided into Quaternary (o) and "all others" $(\bullet)$ on the basis of uranium series dating (Burnett et al., in Suess and Thiede 1983).

surface was considerably different from today and when coastal upwelling took place on different scales in other geographic locations and in different climatological settings. Short and long term sea-level changes due to climatic and tectonic processes throughout the entire Phanerozoic have resulted in large displacements of the coastlines (Vail et al., 1977). During times of low sea-level stands, the coastlines were located close to the shelf edge; during times of high stands entire continental platforms were flooded. What were the dimensions of coastal upwelling regimes when coastlines were located close to the shelf edge? Where did upwelling develop in wide shelf seas? How does the sea level respond tc changes of the geoid? How fast can such changes occur, and how do they affect coastal upwelling?

Plate tectonic history and the resulting palaeogeography of our globe have been reconstructed in detail for the past $150-$ 180 million years. Reconstructions of older intervals of the Phanerozoic are considerably more ambiguous, but they do allow the identification of situations where orientation and location of continental margins, mountain chains and oceans were such that upwelling regions could develop in different settings from those of today. The long zonal coastlines developed during Palaeozoic times (Fig. 4), and the asymmetric distributions of continent and ocean during the existence of Pangaea and Panthalassa are cases with no presentday counterparts.

Today, rather peculiar flow patterns are observed in the atmosphere and oceanic water masses because of the devel- opment of an extreme climate in the late Cenozoic which resulted in the cooling of the polar atmosphere and hydrosphere and in the growth of large ice sheets. The steep temperature gradients between the poles and the equator are important forcing functions of the atmospheric circulation and of the oceanic current regimes. In contrast, 60-120 million years ago the polar oceans were relatively warm and the oceanic bottom-water current regimes relatively sluggish. Black shales were deposited over wide areas of the Cretaceous oceans and shelf seas. Was coastal upwelling during these times an important process in the formation of vast volumes of marine hydrocarbon source rocks? Can we use our knowledge about the effectiveness and location of modern upwelling regimes to predict where large quantities of organic carbon might have accumulated during the geologic past? Do we have enough data to model flow patterns of the atmosphere and of the oceanic water masses in sufficient detail to locate former upwelling regimes?

Little is known about the possibilities of when and how the chemistry of ocean water masses and of the atmosphere might have changed through geologic time. Recent studies suggest that the relationship between fluxes of nutrients in freshwater run-off from land and in hydrothermal solutions from the ocean crust might have varied greatly through time (e.g., Edmond et al., 1982). Were such changes of consequence to the chemistry of upwelling facies? How did the marine ecosystems, especially those of coastal upwelling regimes, respond to changes in the amount and composition of available nutrients? Answers to these questions are not now available.

The organisms of the present ecosystems of coastal upwelling regimes, as summarized by Barber and Smith (1981), provide us with some of the most readily identifiable signals of upwelling in the underlying sediments. However, some major plankton groups such as diatoms, coccolithophorids and foraminifers, as well as many of the organisms of the higher trophic levels, have only evolved since mid-Mesozoic times. We do not even have fragmentary knowledge of how ancient marine food-webs might have been constructed, of the characteristics of profiles of dissolved silica and other nutrients before the mid Mesozoic, or of which organisms produced the large quantities of organic material preserved in the early Phanerozoic upwelling records. These concerns explain why ancient upwelling records are so difficult to interpret.

\section{Signals of Upwelling}

Studies of the sediments under the modern upwelling regimes have clearly demonstrated how the various signals generated by coastal upwelling are selectively preserved and thereby partially reduced and obliterated. The fate of organic matter during sedimentation in upwelling regimes illustrates this issue well. First-order comparison of upwelling and non-
Figure 4: Mississippian phosphorites (4), cherts (๑) and organic-carbonrich rocks (n). Palaeogeography: No pattern on continents = low lands; diagonal $=$ continental shelves; stippled $=$ high lands; large dotted pattern = coastal upwelling. Modified from Parrish et al., in Thiede and Suess, 1983.

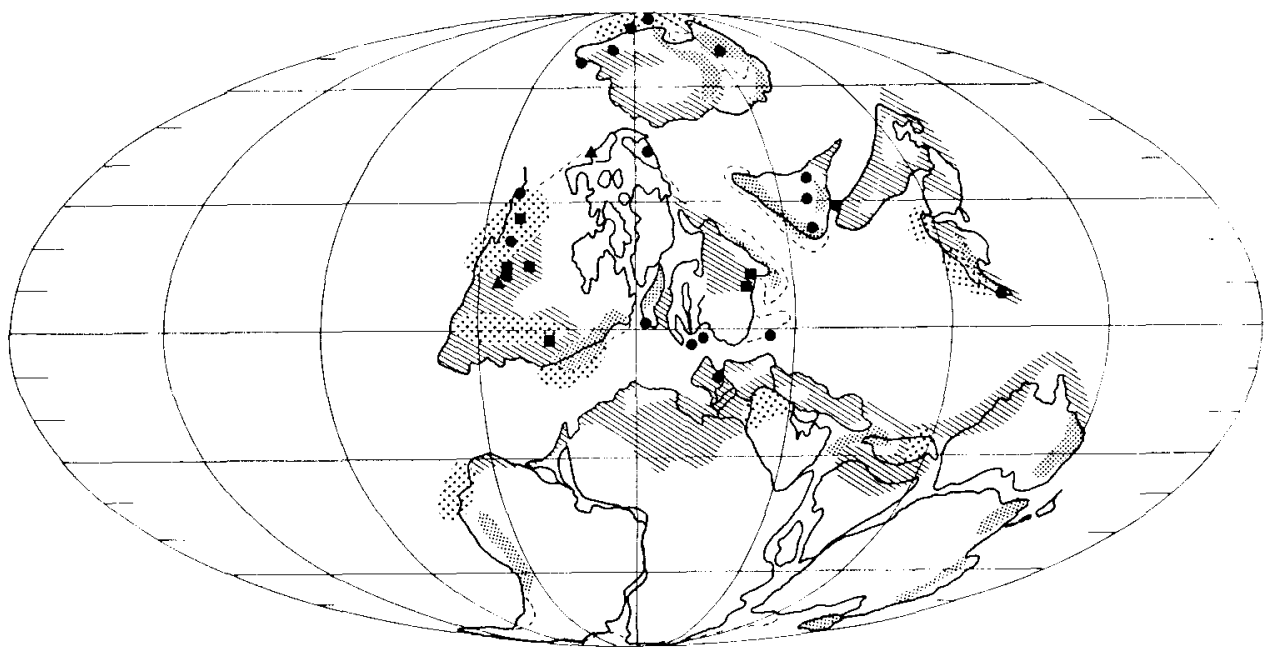


upwelling environments indicate that only $15-35 \%$ of the organic matter produced at the sea surface reaches $100 \mathrm{~m}$ of water depth in the upwelling environments, but $20-60 \%$ of production reaches that same depth in neritic waters. Such differences in fluxes are of immense significance for organic matter sedimentation. If related to modes of particle transport they could contain much valuable ecological information. For example, one mode that distinguishes the Peruvian upwelling system from other near-shore ecosystems is fast-sinking anchoveta fecal pellets. That transfer mechanism provides an important link between biological production in the euphotic zone and the sediments off Peru.

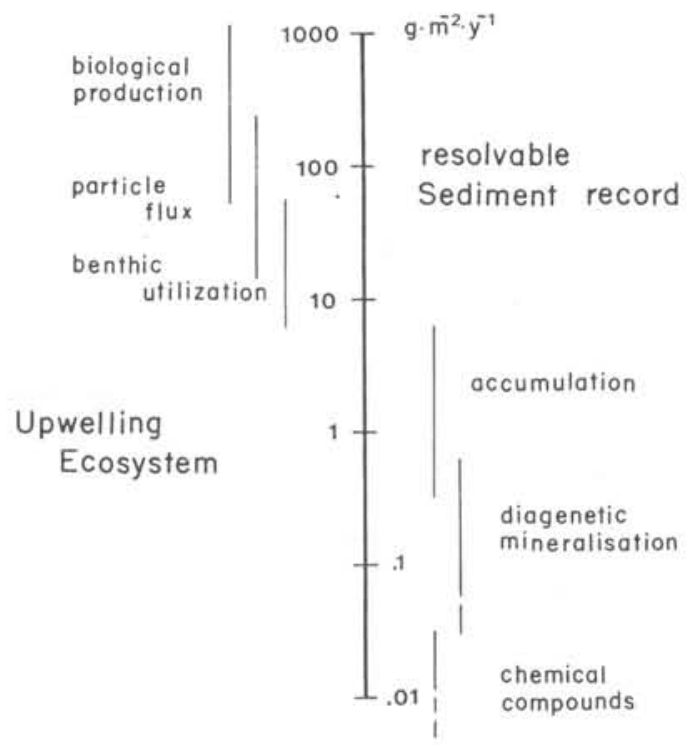

Figure 5: Changes in flux rates (in grams per square meter per year) of organic matter in an upwelling ecosystem between initial production in surface waters to eventual burial in sediments.

Figure 5 shows schematically the loss of organic matter during transfer from initial bioproduction to eventual burial. Of $500 \mathrm{~g}$ of carbon produced in every square meter of sea surface per year, $20 \%$ is transported by particle settling to the seafloor where half is used by benthic organisms, leaving only $50 \mathrm{~g}$ to accumulate. Early diagenesis then removes another 15 to $40 \mathrm{~g}$ from the sediment column so that the amount of carbon finally preserved represents the minutest fraction of what was initially present. Even after burial, alterations continue to obliterate the sediment components by interaction with sedimentary pore fluids and under the influence of changing temperatures and pressures. Of the more important components of upwelling facies observed in the geologic record (Garrison, 1981), siliceous components may be altered to chert and organic carbon to hydrocarbons and/or carbonates.

The recent work thus clearly demonstrates the increasing difficulty of identifying upwelling regimes with increasing age of the sedimentary record. Despite this the facies associations remain remarkably consistent, with their black shales, phosphorites, cherts and microfossils, whether formed during Cretaceous, Ordovician or Cambrian upwelling.

\section{References}

Barber, R.T. and Smith, R.L., 1981. Coastal upwelling ecosystems. In: Longhurst, A.R., Analysis of Marine Ecosystems, Academic Press, London, p. 31-68

Brongersma-Sanders, M., 1948. The importance of upwelling water to vertebrate paleontology and oil geology. Ver- handelingen der Koninklijke Nederlandsche Akademie van Wetenschappen, Afd. Natuurkunde, Sec. 2, v. 45(4), 112p.

Edmond, J.M., Von Damm, K.L., McDuff, R.E. and Measures, C.I., 1982. Chemistry of hot springs on the East Pacific Rise and their effluent dispersal. Nature, v. 297, p. $187-$ 191.

Garrison, R.E. (ed.), 1981. The Monterey Formation and Related Siliceous Rocks of California. Society of Economic Paleontologists and Mineralogists, Pacific Section, Bakersfield, 327p.

Hartline, B.K., 1980. Coastal upwelling: physical factors feed fish. Science, v. 208, p. 38-40.

Hempel, G. (ed.), 1982. The Canary Current: Studies of an Upwelling System. Rapports et Procès-verbeaux des réunions, Conseil International pour l'Exploration de la Mer, v. 180 , Copenhagen, $455 \mathrm{p}$.

Longhurst, A.R. (ed.), 1981. Analysis of Marine Ecosystems. Academic Press, London, $741 \mathrm{p}$.

Richards, F.A. (ed.), 1981. Coastal Upwelling. Coastal and Estuarine Sciences V. 1, American Geophysical Union, Washington, 529p.

Suess, E. and Thiede, J. (eds.), 1983. Coastal Upwelling: Its Sediment Record, Part A: Responses of the Sedimentary Regime to Coastal Upwelling. Plenum Press, New York, $602 \mathrm{p}$.

Sverdrup, H.U., Johnson, W.M. and Fleming, R.H., 1942. The Oceans. Prentice Hall, Englewood Cliffs, 1087p.

Thiede, J. and Suess, E. (eds.), 1983. Coastal upwelling: Its Sediment Record, Part B: Sedimentary Records of Ancient Coastal Upwelling. Plenum Press, New York, 617p.

Vail, P.R., Mitchum, R.M. and Thompson, S., 1977. Seismic stratigraphy and global changes of sea level, Parts 3 \& 4, American Association of Petroleum Geologists, Memoir, v. 26 , p. 63-97.

\section{ABOUT THE AUTHORS:}

Prof. Erwin Suess is a marine geochemist located at the School of Oceanography, Oregon State University (Corvallis, Oregon 97331, U.S.A.). His current research activities involve the chemical fractionation of biogenic elements in the oceans, the processes of sediment lithification along subducting plate boundaries, and the relationship between bioproductivity, sedimentation rate and the preservation of organic matter in sediments and rocks.

Prof. Jörn Thiede recently moved from Norway to the Department of Geology \& Palaeontology, Kiel University (Olsenhausenstrasse 40/60, D-2300 Kiel, F.R.G.). He has worked for many years on the distribution of skeletal plankton in surface waters and sediments, on the palaeoceanography of coastal upwelling regimes and on the history of deep-sea sedimentation in the Pacific, Atlantic and Indian oceans. Prof. Thiede is Secretary of the IUGS Commission for Marine Geology.
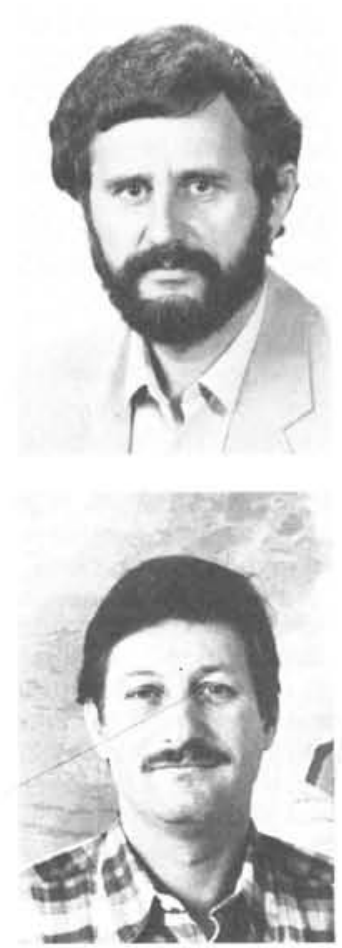